\title{
EL SISTEMA DE ACREDITAMIENTO DEL IVA EN 1980: UN ACERCAMIENTO PARA ENTENDER LAS PROBLEMÁTICAS ECONÓMICAS Y POLÍTICAS DE LA ADMINISTRACIÓN FISCAL EN MÉXICO
}

\author{
THE VAT ACCREDITATION SYSTEM IN 1980: \\ AN APPROACH TO UNDERSTANDING \\ THE ECONOMIC AND POLITICAL PROBLEMS \\ OF TAX ADMINISTRATION IN MEXICO
}

\author{
María del Ángel Molina Armenta* \\ Universidad Veracruzana, Instituto de Investigaciones \\ Histórico-Sociales, México \\ madelangel.molina@gmail.com \\ https://doi.org/10.36105/iut.2021n33.06 \\ Recibido: 04/08/2021 \\ Aceptado: 13/09/2021
}

\section{RESUMEN}

El objetivo del presente artículo es analizar el sistema de acreditamiento del IVA y las reformas administrativas que le dieron operatividad con la intención de mostrar la estrecha relación entre la administración hacendaria con los objetivos y problemáticas económicas y políticas implícitos en el fenómeno tributario. Sostenemos que el sistema de acreditamiento coadyuvó a alcanzar los objetivos de la coordinación fiscal del comercio y la industria en tanto colocó al contribuyente como agente clave de la recaudación federal y restó importancia a las entidades

Esta investigación tuvo lugar en el marco de las Estancias Posdoctorales Nacionales del Conacyt. La autora realiza una estancia de investigación (2do. año) bajo la responsabilidad académica de la Dra. Yovana Celaya en el IIH-S de la UV. 
federativas para definir el monto de la misma. También, sostenemos la idea de que las modificaciones administrativas que implicó respondieron a dos problemas relacionados con el ISIM. El primero, de carácter económico, es la baja recaudación que éste reportó para el erario federal durante su vigencia; y el segundo, de naturaleza política, es la debilidad de las entidades federativas para participar en la administración de la imposición indirecta que se pronunció tras la reforma a la tasa del ISIM de 1973.

Palabras clave:

Coordinación fiscal, comercio e industria, IVA, sistema de acreditamiento, ISIM.

\section{Abstract:}

The objective of this article is to analyze the VAT accreditation system and the administrative reforms that made it operational with the intention of showing the close relationship between the tax administration and the economic and political objectives and problems implicit in the tax phenomenon. We maintain that the accreditation system helped to achieve the objectives of the fiscal coordination of commerce and industry in that it placed the taxpayer as a key agent of federal collection and played down the importance of the federal entities in defining the amount of it. We also support the idea that the administrative changes involved responded to two problems related to ISIM. The first of an economic nature, is the low collection that it reported for the federal treasury during its validity; and the second of a political nature, is the weakness of the federal entities to participate in the administration of indirect taxation that was pronounced after the reform of the ISIM rate of 1973.

Keywords:

Tax coordination, trade and industry, VAT, accreditation system, ISIM.

\section{INTRODUCCIÓN}

Con el establecimiento del Impuesto al Valor Agregado (IVA) en México, en 1980, concluyó el proceso de coordinación fiscal del comercio y la industria que se impulsó a través del Impuesto Sobre Ingresos Mercantiles (ISIM), vigente desde 1948. En este sentido, para la federación, su entrada en vigor significó la materialización tanto de su intención económica por establecer un impuesto sobre el consumo final; como de su propósito político por concentrar en su jurisdicción, las facultades tributarias del ramo. Uno de los elementos del diseño del IVA que tuvo crucial importancia para alcanzar estos objetivos fue el sistema de acredita- 
miento que representó una verdadera novedad en la forma en que la federación se hacía de recursos a través de las transacciones realizadas por comerciantes e industriales.

En este marco, el objetivo del presente artículo es ofrecer al lector un análisis del sistema de acreditamiento y de las reformas administrativas que le dieron operatividad con la intención de mostrar la estrecha relación que guarda la administración hacendaria con los objetivos y problemáticas económicas y políticas implícitos en el fenómeno tributario. Lo que sostenemos en este sentido es que el sistema de acreditamiento coadyuvó a alcanzar los objetivos de la coordinación fiscal del comercio y la industria en la medida en que colocó al contribuyente como agente clave de la recaudación federal y restó importancia a las entidades federativas para definir el monto de la misma. Así mismo, sostenemos la idea de que las modificaciones administrativas que implicó respondieron a dos problemas relacionados con el ISIM. El primero, de carácter económico, es la baja recaudación que el ISIM reportó para el Erario federal durante su vigencia (19481980); y el segundo, de naturaleza política, es la debilidad de las entidades federativas para participar en la administración de la imposición indirecta que se pronunció tras la reforma a la tasa del ISIM de 1973. Para cumplir con este objetivo, hemos estructurado el análisis en tres apartados. En el primero contextualizamos el establecimiento del IVA, es decir, la sustitución del ISIM, en el marco del proceso de coordinación fiscal de las transacciones mercantiles y desarrollamos los elementos esenciales del sistema de acreditamiento. La segunda y tercera sección se encargan de estudiarlo desde los problemas y objetivos político-económicos a los que respondió; y desde las dos principales reformas administrativas que le dieron funcionalidad: las relacionadas con los documentos probatorios y las declaraciones.

Esta propuesta analítica, al tratar de mostrar cómo el diseño de un impuesto y el esquema administrativo que lo dota de operabilidad responden a objetivos y problemáticas político-económicas tan propias del fenómeno tributario, representa un esfuerzo por reconocer en estas cuestiones una fuente importante de definición y reforma del esquema administrativo. Intentamos así, acercarnos al estudio de la administración hacendaria mexicana desde una perspectiva histórica que la problematiza como expresión del arreglo fiscal bajo el que se recaudó y distribuyó la riqueza pública a inicios de la década de los ochenta. En términos historiográficos pretendemos, aunque de manera inicial, avanzar en los escasos estudios sobre la historia de los impuestos del siglo xx en México e inscribirnos en la intención de este trabajo colectivo de brindar, como señalan los coordinadores, un enfoque desde la perspectiva de la administración pública que nos permita comprender cómo se entremezclan la legislación, el desempeño económico, las cuestiones políticas y la fiscalidad. ${ }^{1}$

1 Las obras principales que los coordinadores han desarrollado sobre esta problemática son: JÁUREGUI, Luis, La Real Hacienda, 1999 y BeCERrIL, Carlos, “Administrativizar”, 2013. 


\section{LA SUSTITUCIÓN ISIM-IVA EN 1980, LA COORDINACIÓN FISCAL DE LAS TRANSACCIONES MERCANTILES Y EL SISTEMA DE ACREDITAMIENTO}

Con la entrada en vigor del IVA en México, el $1^{\circ}$ de enero de 1980, la federación alcanzó, principalmente, dos objetivos en materia de coordinación fiscal: uno de carácter económico relacionado con el establecimiento de un impuesto que recayera sobre el consumo final; y otro, político, vinculado con la centralización de facultades tributarias bajo su jurisdicción. Para entender el objetivo económico es necesario hacer hincapié, en primer lugar, en el diseño mismo del IVA. En el artículo $1^{\circ}$ de la Ley que le dio vigencia, se define el objeto gravable en los siguientes términos:

Están obligadas al pago del impuesto al valor agregado establecido en esta Ley, las personas físicas, las morales o las unidades económicas que, en territorio nacional, realicen los actos o actividades siguientes:

\section{i. Enajenen bienes \\ ii. Presten servicios independientes \\ iii. Otorguen el uso o goce temporal de bienes \\ iv. Importen bienes y servicios}

El impuesto se calculará aplicando a los valores que señala esta Ley la tasa del $10 \% .^{2}$

Como denota la cita, este impuesto grava, en términos generales, la compraventa. Al igual que el ISIM es un impuesto plurifácico en vista de que recae sobre el total de las transacciones que supone la actividad económica, es decir, fiscaliza tanto la demanda intermedia como la final de bienes y servicios. La primera refiere la destinada a otro proceso productivo, mientras que la segunda alude al consumo final. A grandes rasgos, las transacciones industriales son representativas de la primera, al tiempo que las transacciones de comerciantes de las segundas, en tanto que éstos constituyen el eslabón de la cadena de distribución que oferta la producción para el consumo final de las familias (como agente económico). ${ }^{3}$ Sin embargo, a diferencia de su antecesor, el IVA, a pesar de recaer sobre la demanda total, es exclusivamente pagado por el consumidor final gracias al sistema de acreditamiento que precisa un pago fraccionado del mismo. Este aspecto del diseño del IVA lo definió como una figura tributaria más avanzada que el ISIM.

Técnicamente, el sistema de acreditamiento se entiende como el saldo del débito y crédito fiscal. Lo anterior significa que el contribuyente sólo reporta al fisco la diferencia entre el IVA que cobró en sus ventas (es decir, el que trasladó

2 Ley del Impuesto al Valor Agregado, 1979, pp. 766-767. En el artículo $2^{\circ}$ se estableció una tasa del 6\% para la franja fronteriza de $20 \mathrm{~km}$ paralela a la línea divisoria internacional del norte del país y para las zonas libres de Baja California y Norte de Sonora y de Baja California Sur.

3 Cabe aclarar que esta conceptualización tiene la intención de simplificar nociones que están presentes a lo largo del documento. No niegan en ningún sentido, la complejidad de la esfera de la distribución en la que existen una cantidad importante de intermediarios o industriales que venden sin éstos, su producción. 
al demandante) y el que pagó en las adquisiciones que realizó durante el mismo periodo (es decir, el que le fue trasladado como demandante). Ambos montos están determinados por la tasa del IVA. Su obligación tributaria resulta de restar ambos conceptos como muestra el EsQUEMA 1 de manera más sencilla. Esta es justo la mecánica del sistema de acreditamiento: deducir del impuesto a pagar al fisco, el impuesto pagado en la compra anterior, es decir, obtener un crédito fiscal a favor del contribuyente. En la ley federal de IVA de 1980 el planteamiento se presentó del siguiente modo: "el acreditamiento consiste en restar de la cantidad que resulte de aplicar a los valores señalados en esta Ley [es decir, a las compraventas], la tasa a que se refiere el artículo $1^{\circ}[10 \%]$, o en su caso, la del artículo $2^{\circ}[6 \%]$, el impuesto al valor agregado que le hubiera sido trasladado al contribuyente $[\ldots] .^{4}$

ESQUEMA 1

Sistema de acreditamiento (definición)

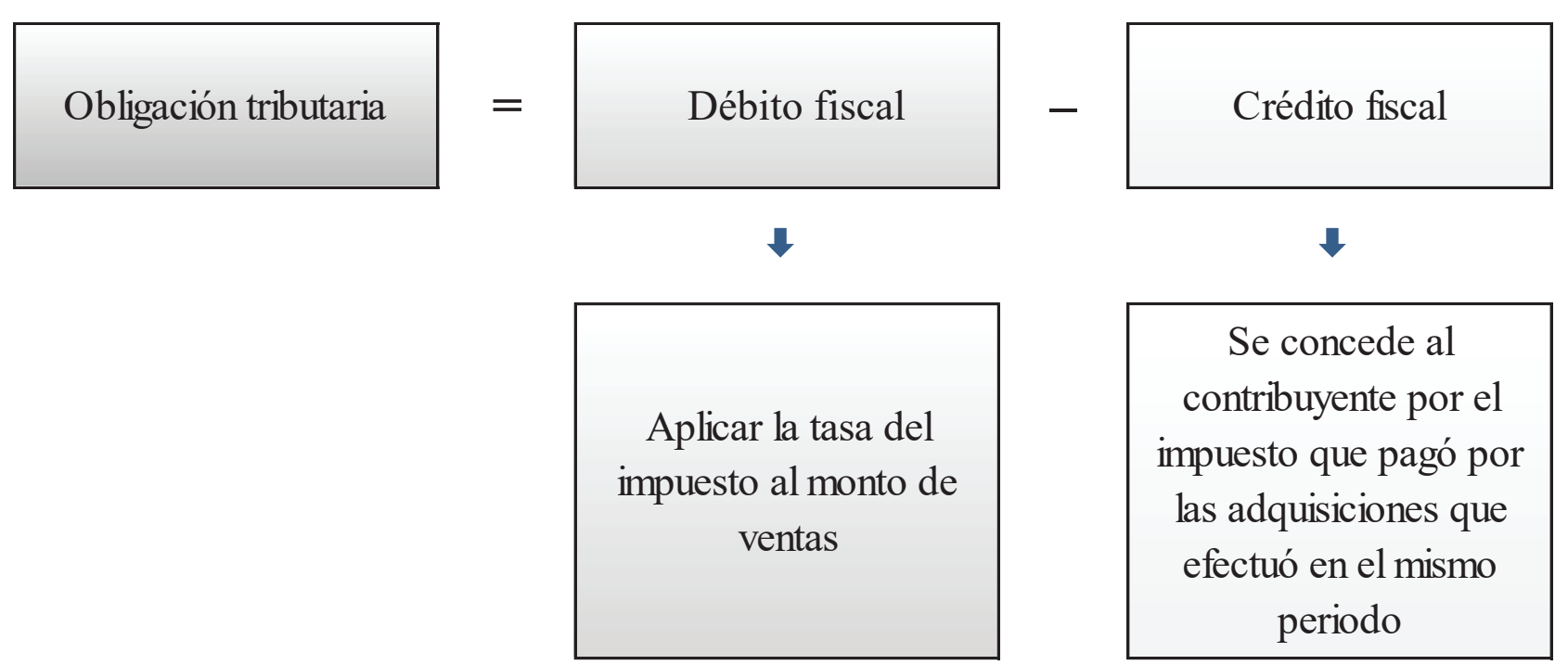

Fuente: Elaboración propia con base en Ley del Impuesto al Valor Agregado, 1979.

Lo que sucede bajo esta dinámica es que en cada etapa del ciclo económico se "adelanta" una parte del impuesto que el consumidor debe pagar. De aquí que el sistema de acreditamiento se traduzca en una recaudación que se obtiene de manera diferida en la medida en que tiene lugar el ciclo de producción y distribución de los bienes y servicios. Para dejar más claro cómo es que el IVA es un impuesto que grava el consumo final de manera fraccionada, vale la pena considerar el ejemplo de la TABLA 1. Asumiendo la tasa del $10 \%$ con la que entró en vigor el IVA, podemos comenzar la explicación señalando que, en la actividad económica ilustrada en ella, participan tres agentes económicos: un fabricante, un mayorista y un detallista. El primero de éstos, cuando compra a su proveedor los

$4 \quad$ Ley del Impuesto al Valor Agregado, 1979. Los corchetes son nuestros. 
insumos necesarios para producir, paga 5 pesos por concepto de IVA. De este modo, adquiere su crédito fiscal. Una vez concluida su operación, vende al mayorista su producción en 150 pesos y retiene (cobra) 15 pesos por concepto de IVA que constituyen su débito fiscal. Siguiendo entonces la lógica del sistema de acreditamiento, esta agente entera al fisco la diferencia entre uno y otro, es decir, la que resulta de restar al impuesto que trasladó, el que le fue trasladado por su proveedor: 10 pesos.

La producción continúa su circulación con el mayorista quién, como ya dijimos, le fue trasladado un IVA de 15 pesos al momento de comprar al fabricante. Este segundo agente económico (el mayorista), vende la producción al detallista en 200 pesos trasladándole un IVA de 20 pesos. Bajo la misma lógica, le entera al fisco sólo 5 pesos. La producción llega al consumidor final cuando el detallista se la vende en 300 pesos y le traslada, además, un IVA de 30 pesos. Al hacer la deducción del IVA que le fue trasladado ( 20 pesos) al IVA que trasladó (30 pesos), sólo paga el fisco 10 pesos. Como observará el lector en la misma tabla, es el consumidor final quien soporta el pago del impuesto (30 pesos) mientas que las transacciones intermedias, en realidad, no pagan ningún impuesto. Esto es posible debido a que cada agente económico previo al consumidor final puede recuperar el IVA que le fue trasladado. Pero a la vez, cada intermediario entrega al fisco una fracción del impuesto que pagará el consumidor final: los proveedores del fabricante enteraron 5 pesos, el fabricante 10 pesos, el mayorista 5 pesos y el detallista 10 pesos.

\section{TABLA 1}

Mecánica de funcionamiento del sistema de acreditamiento (Tasa del IVA: 10\%)
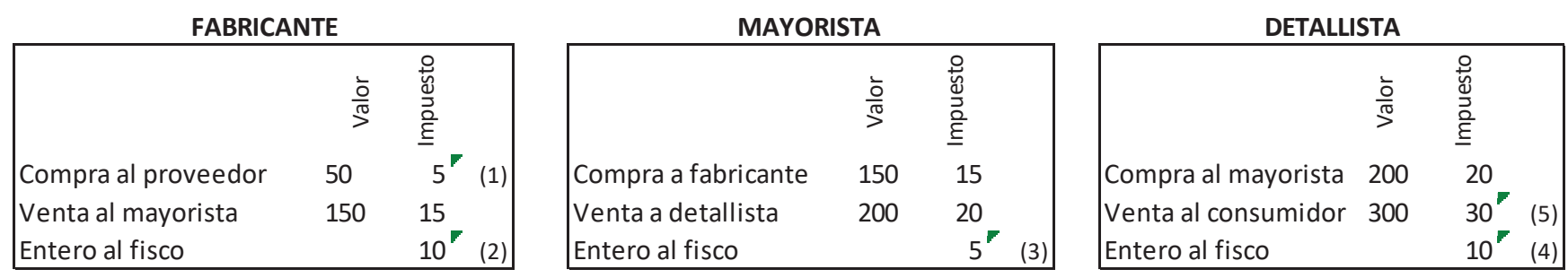

RESUMEN

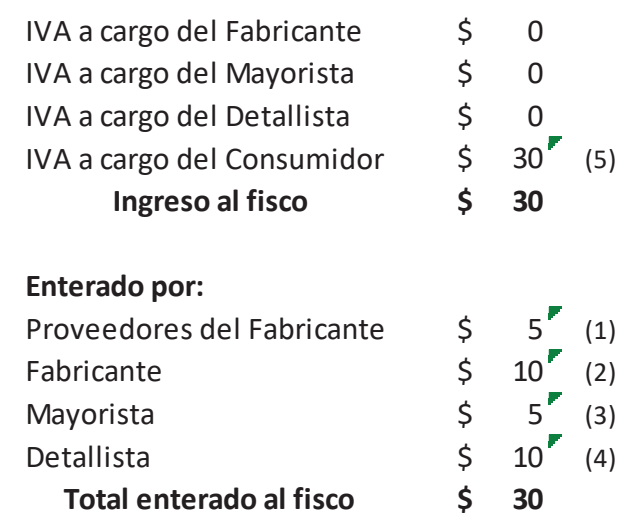

Fuente: Paras Pages, Jiménez Delgado, Impuesto, 1972, p. 9. 
En segundo lugar, debemos indicar que, en el discurso federal de aquellos años, la imposición del IVA se justificó en términos económicos, grosso modo, a partir de la importancia de modernizar la tributación indirecta en el país y, sobre todo, en función de su neutralidad sobre los precios que el sistema de acreditamiento supone. El "efecto cascada" del ISIM — que retomaremos más adelante- y su presión sobre el nivel de éstos representaron uno de los principales argumentos para impulsar su establecimiento, sobre todo en un escenario macroeconómico caracterizado por altos índices de inflación y tasas de crecimiento que mostraban el agotamiento del modelo sustitutivo de importaciones que llamaban con urgencia a una reforma fiscal de gran envergadura que anclara la recaudación indirecta con la dinámica de la economía nacional. ${ }^{5}$

En la exposición de motivos de la Ley de Ingresos que presentó José López Portillo, entonces presidente de México, a la Cámara de Diputados en diciembre de 1977 se advertía de esta necesidad. Pero también se subrayaba la imposibilidad de impulsar una reforma fiscal significativa en un escenario macroeconómico adverso:

El Ejecutivo Federal está consciente de que el sistema tributario se ha quedado rezagado frente a la evolución económica y social del país. Requiere de revisiones de fondo que le permitan cumplir mejor objetivos fiscales y de justicia social, tanto como los relacionados a crear condiciones estimulantes al desarrollo de las actividades productivas. Del mismo modo, necesita generalizarse, simplificarse y aplicarse con mayor eficiencia.

Sin embargo, el rezago acumulado en la revisión del sistema impositivo ha creado una serie de circunstancias de hecho que magnifican su incidencia en la presente coyuntura de la economía nacional. Por eso, cabe reiterar que no se ha pretendido llevar a cabo reestructuraciones espectaculares [...].

Con todo, el Ejecutivo Federal mantiene el firme compromiso de transformar y adecuar el sistema tributario federal. Después de realizar los estudios indispensables, examinar en detalle las repercusiones y efectuar consultas, se propondrán las modificaciones más convenientes, dentro de una estrategia que concibe a la Reforma Fiscal, no como un acto súbito y discontinúo, sino como un proceso permanente de actualización y modernización, congruente con la evolución y grado de cumplimiento de las metas del desarrollo. ${ }^{6}$

Fue a propósito del efímero repunte que la economía mexicana reportó en 1978 tras el descubrimiento de los yacimientos petroleros de Campeche y Tabasco y el aumento en la recaudación que los mismos supusieron, que la federación

5 Entre 1971 y 1976, la tasa de crecimiento promedio anual del PIB fue del 6\%. En cambio, para 1977, apenas llegó al 3.4\%. La inflación, por su parte, presentó un incremento por demás considerable: entre 1971 y 1976, la tasa de inflación anual promedio alcanzaba los 14.9 puntos porcentuales que rebasaba por mucho el 3\% que se había mantenido entre 1958 y 1970. Moreno BrID, Juan Carlos y Ross Bosch, Jaime, Desarrollo y crecimiento, 2012, p. 174.

6 Ibarra Muñoz, David, Política financiera, 1980, pp. 27-28. Para entonces, el Ejecutivo federal señalaba que su objetivo era alcanzar metas moderadas de crecimiento - comparadas con las que se habían presentado en años anteriores - que buscaban superar los efectos de la crisis coyuntural de fines de 1976. Lo que se buscaba en este sentido, fueron principalmente, combatir la inflación y corregir los desequilibrios financieros y de pagos externos. Ibarra Muñoz, David, Política financiera, 1980, p. 15. 
retomó sus esfuerzos por modernizar la tributación indirecta a través del IVA. ${ }^{7}$ En la Ley de ingresos de ese mismo año, el ejecutivo federal reconocía en su establecimiento un paso sustancial en ese sentido. ${ }^{8}$ Un mes después, el 29 de diciembre de 1978, se publicó en el Diario Oficial de la Federación la Ley del Impuesto al Valor Agregado que entraría en vigor un año después, es decir, a partir del $1^{\circ}$ de enero de 1980, como hemos señalado. Entre los motivos que la federación utilizó para justificar este periodo de gracia fue la necesidad de impulsar un arduo proceso de divulgación del tránsito ISIM-IVA para reducir los riesgos psicológicos de un posible impacto inflacionario a la hora de introducir el nuevo impuesto, así como la de preparar los cambios administrativos que se encargarían del manejo del gravamen. De esta manera, en la iniciativa de la Ley de Ingresos para 1980, respecto a la imposición del IVA, se lee:

El haber programado que la nueva ley iniciara su vigencia doce meses después de haber sido aprobada permitió una comunicación amplia con todos los sectores sociales, a fin de recoger sus observaciones constructivas y revisar a fondo su contenido y concordancia con la realidad económica nacional, así como preparar los órganos administrativos que habrán de manejar el nuevo sistema.

Como resultado de estas labores preparatorias se proponen modificaciones orientadas a esclarecer conceptos y su expresión en la Ley, a facilitar el tránsito de un sistema a otro y a reducir los riesgos psicológicos de un posible impacto inflacionario, principalmente sobre los artículos que determinan los niveles de vida de los grupos mayoritarios de la población. ${ }^{9}$

Otra cuestión que debemos apuntar es que el establecimiento de un impuesto al consumo final fue una intención federal presente desde los últimos años de la década de los cuarenta que se inscribió, a su vez, en el proceso de coordinación hacendaria que impulsaron los diferentes gobiernos posteriores a la Revolución Mexicana durante toda la primera mitad del siglo Xx, con la intención principal de reorganizar y modernizar la hacienda pública nacional. ${ }^{10}$ En las discusiones hacendarias que tuvieron lugar a propósito de la Tercera Convención Nacional Fiscal de 1947, se manifestó la aspiración federal de establecer un impuesto de esta naturaleza tomando como referencia el sell tax entonces vigente en los Estados Unidos en tanto suponía diversas ventajas económicas y administrativas para fiscalizar la compraventa. ${ }^{11}$ La principal característica de éste es que recae en una sola etapa del proceso de comercialización, a saber, la venta del detallista al consumidor final, es decir sobre la demanda final. En estos términos, y a diferencia del ISIM y del IVA, es un impuesto monofase. El establecimiento de un impuesto como éste, suponía desgravar las transacciones que atendían la demanda intermedia. En este sentido, Yáñez Ruíz, reconocido fiscalista y asesor federal de aquellos años, sostenía que el establecimiento del sell tax en México conduciría

\footnotetext{
Molina Armenta, María del Ángel, "El establecimiento", 2019.

IbARra MuÑoz, David, op. cit., p. 155.

Ibidem, pp. 292-293.

10 Para conocer esta problemática, véase ABoites Aguilar, Luis, Excepciones, 2003.

11 Véase YÁÑEz Rú́z, Manuel, El problema, 1958, tomo IV, pp. 317-332.
} 
a "[...] gravar la venta [...] sobre la cual el comprador tenga el propósito evidente de consumirla y no de revenderla". ${ }^{2}$

No obstante, existieron limitantes para tal propósito. Entre éstas, destacan las relacionadas con la administración del gravamen federal que en aquellos años recaía sobre las transacciones mercantiles, a saber, el impuesto del timbre establecido desde el porfiriato. En la Convención que recién referimos, Ramón Beteta, entonces Secretario de Hacienda, señalaba que dicha dificultad se originaba en la forma de pago del timbre que no permitía conocer si los causantes se dedicaban a actividades industriales o alguna actividad de intermediación comercial, es decir, a atender la demanda intermedia de bienes y servicios: "[...] pero si se tratara de establecer el impuesto al consumo se requeriría eliminar del total de las ventas [...], las que representen ventas de industriales y de mayoristas efectuadas con propósito de reventa, y no hay de por ahora manera alguna de hacer esa eliminación porque la forma de pago del impuesto del timbre no permite conocer ni quiénes son los causantes que lo pagan, ni cuanto paga cada causante". ${ }^{13}$

Bajo ese escenario, si se pretendía averiguar el monto de los ingresos derivados de las ventas al consumo final tan indispensables para establecer el sell tax, resultaba necesario, en principio, conocer el monto de las transacciones intermedias a través de una figura que recayera sobre el total de las transacciones económicas, cuya declaración, ofreciera los datos necesarios para conocer dicho monto. De aquí, que la imposición del impuesto sobre el consumo final debía ser antecedida por el establecimiento de una figura que gravara el total de las ventas comerciales, es decir, de carácter plurifásico: el IsIM. Fue así que éste gravó el conjunto de transacciones mercantiles con una intención transitoria en términos económicos: mientras se contaba con las condiciones para establecer un impuesto sobre el consumo final, se establecía otro que fiscalizaba también la demanda intermedia.

Con el paso de los años, en el contexto de las nuevas posibilidades de desarrollo que ofrecía el intercambio comercial internacional, la federación tornó su atención a finales de los años setenta hacia las experiencias europeas que gravaban el consumo final a través del valor agregado a propósito de la conformación de la Comunidad Económica Europea (CEE). En la justificación de motivos de la ley con la que entró en vigor el IVA, la federación argumentaba a favor de su establecimiento con base en la entonces reciente experiencia internacional europea. ${ }^{14}$ De este modo, el establecimiento del IVA en México significó, en cierto sentido, un viraje en la figura tributaria con la que gravaría el consumo final: abandonaba la idea de los años cuarenta de establecer un impuesto monofase como el sell tax y conservaba la idea de un impuesto plurifase como el ISIM.

En relación con el objetivo de carácter político, debemos retomar en principio, el proceso de coordinación fiscal que mencionamos en líneas anteriores. Este cometido, que inicialmente respondió a las distintas necesidades financieras y

12 YÁÑez Ruíz, Manuel, El Problema, 1958, tomo IV, Libro tercero, p. 320.

13 Ibidem, p. 302.

14 Véase Exposición de motivos de la Ley del Impuesto al Valor Agregado, 1979. 
políticas del contexto posrevolucionario, se afianzó en la medida en que el proyecto de industrialización de los años cuarenta, exigió una mayor intervención del Estado y sus recursos en la actividad económica. La reorganización hacendaria pugnó, principalmente, por la coordinación del sistema tributario nacional. Coordinar los impuestos, en aquellos años, significó centralizar los ingresos tributarios en tanto implicó el establecimiento de una sola figura tributaria de carácter federal en cada uno de los ramos donde ésta concurría con impuestos locales (estatales y municipales). En la narrativa federal, esta forma de unificar la tributación nacional, además de acabar con la "anarquía fiscal" que resultaba de la concurrencia, representaba un requisito indispensable para facilitar y acelerar el crecimiento de la actividad económica. Este esfuerzo de reorganización, hay que decir, también pugnó por el establecimiento de figuras tributarias federales de carácter directo que coadyuvaran a mejorar la distribución del ingreso y a disminuir la dependencia de los ingresos fiscales de los impuestos relacionados con el comercio exterior. Con el establecimiento del Impuesto Sobre la Renta (ISR) en 1925 y el importante monto de recaudación que reportó a partir de los años cuarenta se avanzó, no sin dificultades, en dichas pretensiones. ${ }^{15}$

En segundo lugar, no debemos perder de vista que en materia de las transacciones realizadas por industriales y comerciantes, el ISIM representó el impuesto con el que la federación impulsó la centralización fiscal del ramo. Desde los años sesenta del siglo XIX hasta 1948, éstas fueron gravadas por la federación a través del impuesto del timbre y por las haciendas locales por medio de diversas figuras tributarias entre las que destacan el impuesto de patente y el de compraventa. ${ }^{16}$ Argumentado, entre otras cuestiones, las inconveniencias del primero para el desarrollo de las transacciones a gran escala y adjetivando de "alcabalatorios" a los segundos, la federación definió una mecánica de coordinación gradual cuya columna vertebral fue el ISIM: con su entrada en vigor se eliminó el impuesto federal del timbre y se invitó a las entidades federativas a derogar los impuestos locales a través de la firma de convenios de coordinación en los que éstas recibían una participación de la recaudación federal obtenida a través del ISIM para resarcir el ingreso tributario sacrificado tras la suspensión de su facultad por fiscalizar el ramo. La forma de distribuir la recaudación del entonces nuevo impuesto fue un esquema de dos tasas: una federal del $1.8 \%$ con vigencia nacional que no dependía de la coordinación y otra local del 1.5\% que sólo se cobraría en caso de celebrarse el respectivo convenio.

De esta forma, el ISIM adquirió un carácter transitorio doble: mientras las entidades federativas se coordinaban y se definía un esquema centralizado en el rubro, se avanzaba en el camino que llevaría al establecimiento de un impuesto sobre el consumo final. Esta última pretensión, dependió, en realidad de la primera: mientras las haciendas locales no estuvieran coordinadas en la materia, las

\footnotetext{
15 Véase Aboites Aguilar, Luis, Excepciones, 2003, cap. 4; y, Aboites Aguilar, Luis, y Unda Gutiérrez, Mónica, El fracaso, 2011.

16 Véase Molina Armenta, María del Ángel, “La coordinación”, 2016.
} 
condiciones de sustituir el ISIM por el IVA resultarían más complejas. Este mecanismo, cabe señalar, no tuvo el resultado esperado en tanto implicó importantes conflictos con diferentes actores. Como veremos en el tercer apartado, existieron por momentos tensiones con los principales contribuyentes y, sobre todo, importantes conflictos con las entidades federativas en torno a la distribución de facultades tributarias que concluirían hasta la década de los setenta. La transición política que suponía el ISIM se alcanzó en 1973 cuando todas las entidades federativas estaban coordinadas con la federación en materia de transacciones mercantiles. La transición económica se alcanzó cuando se estableció el IVA. Si consideramos, entonces, la intención federal de inicios del siglo xx por coordinar el ramo, bien podemos reconocer a la sustitución ISIM-IVA como la culminación de dicho esfuerzo: la facultad de imponer sobre el ramo se encontraba bajo su jurisdicción tras un largo y conflictivo camino; y existía una figura tributaria que recaía (y recae) sobre el consumo final.

En la consecución de ambos objetivos, como hemos dicho, el sistema de acreditamiento del IVA y las modificaciones administrativas que tuvieron lugar para darle funcionalidad, jugaron un papel fundamental en tanto que: 1) colocaron al contribuyente en el centro del control de la recaudación y; 2) delegaron a las entidades federativas de la misma, consolidando así la centralización fiscal del ramo. Asimismo, ambos aspectos resultaron, al menos, de dos cuestiones: la baja recaudación que el ISIM reportó durante su vigencia; y la desventajosa posición que, para la década de los setenta, guardaban las entidades federativas en términos de la distribución de facultades tributarias en materia de transacciones mercantiles. Lo que estamos diciendo es que el sistema de acreditamiento coadyuvó a consolidar la coordinación fiscal del ramo; y que los cambios administrativos que implicó respondieron a su vez, a solventar las dificultades económico-políticas en la administración del ISIM: es muy difícil pensar que la federación no estuviera interesada en un mecanismo que resolvería en buena medida el problema de la recaudación indirecta (sobre todo la que resultaba de la evasión) y que las entidades federativas se opusieran al mismo cuando habían perdido cualquier margen de acción sobre la distribución de facultades tributarias tras el establecimiento de la tasa del 4\% del ISIM en 1973.

\section{LA CUESTIÓN ECONÓMICA DEL SISTEMA DE ACREDITAMIENTO: LOS PROBLEMAS DE RECAUDACIÓN DEL ISIM Y LOS CAUSANTES COMO INSPECTORES FISCALES DE OTROS CAUSANTES}

La baja recaudación del ISIM fue un problema que la federación no resolvió con éxito durante su vigencia. Su participación en los ingresos tributarios federales para 1950 apenas alcanzó el 12.15\%. Para 1960 se registró, incluso, una caída que colocó su participación en $10.93 \%$. Sin embargo, y a pesar de que se identifica una ligera mejoría para 1970 cuando su aportación alcanzó los 11.90 puntos porcentuales, su participación siempre fue considerablemente menor a la de otros impuestos como el (ISR) que, a partir de la década de los cuarenta, se posicionó 
como una fuente de ingresos tributarios de gran calado que llegó a aportar para el mismo año, el 34\% de los ingresos tributarios de la federación. ${ }^{17}$

Son muchas las razones que explican este comportamiento en la recaudación del IsIM. Hasta el momento, hemos identificado tres. En primer lugar, se encuentra el lentísimo y accidentado proceso de centralización que la federación impulsó a través de su establecimiento. A reserva de retomarlo con mayor detenimiento en el siguiente apartado, debemos señalar que, para 1952, sin considerar los territorios federales, las entidades federativas que habían accedido a la coordinación participaban con un porcentaje pequeño en la composición de la recaudación que la federación obtenía a través de la tasa del 1.8\% que tenía vigencia nacional. Para entonces, afirmaba un alto funcionario de Hacienda:

[...] sólo se habían coordinado Aguascalientes, Michoacán, Morelos, Querétaro, San Luis Potosí, Sinaloa, Tlaxcala, los Territorios de Quintana Roo y Baja California, que junto con el Distrito Federal fueron coordinados por ley. Estas entidades generaron menos del 50\% de la recaudación que obtuvo la Federación en toda la República. Entre 1953 y 1957, se coordinaron Campeche, Colima, Guerrero, Hidalgo, Puebla, Tabasco y Yucatán, con ellas la recaudación de las Entidades coordinadas representó el $54 \%$ de la federal. ${ }^{18}$

A estas entidades federativas debemos agregarle Durango que se coordinó en 1954. Con ésta, el número de estados ascendió a dieciocho y no varió en mucho tiempo. Para 1970, la recaudación total de las entidades coordinadas, sin considerar al Distrito Federal, sólo llegó a representar el $19.4 \%$ de la recaudación federal total. ${ }^{19}$

En segundo lugar, se encuentran los problemas que el fisco federal sostuvo con los causantes del ISIM. En 1948, por ejemplo, enfrentó un conflicto con comerciantes e industriales encabezados por la Confederación de Cámaras Nacionales de Comercio (CONCANACO) alrededor, principalmente, de la sobretasa del $1.5 \%$ que las haciendas locales podrían cobrar en caso de coordinación. El enfrentamiento fue resuelto por la Secretaría de Hacienda a través de la reducción de esta al $1.2 \%$. La modificación sin duda redujo el potencial recaudatorio del ISIM. $^{20}$ Tenemos también noticia de un conjunto de querellas con los agentes aduanales organizados en la Confederación de Asociaciones de Agentes Aduanales de la República Mexicana (CAAAREM) en relación con el pago del ISIM. El conflicto con este gremio ocurrió de manera paralela al de la CONCANACO y se originó a propósito de la ambigüedad de la legislación del IsIM en relación a las actividades exentas del gravamen. En el ordenamiento inicial de 1948, se reconocía como ingresos exentos del ISIM aquellos que resultaran de actividades profesionales. Los agentes aduanales que habían sido reconocidos como profesionistas por la Secretaría de Hacienda desde 1934, interpusieron un conjunto de juicios de amparo cuando la Dirección General del ISIM le solicitó el pago del

\footnotetext{
17 García Alba Iduñate, Pascual, La evasión, México, 1982, p. 22. Véase Aboites Aguilar, Luis, Excepciones, 2003; y Aboites Aguilar, Luis, y Unda Gutiérrez, Mónica, "El fracaso”, 2011.

19 Subsecretaría de Ingresos, Programa, 1972, p. 8.

20 Véase Molina Armenta, María del Ángel, “La participación”, 2018, pp. 357-397.
} 
impuesto. A diferencia del problema que surgió con la CONCANACO, el conflicto fue llevado hasta la Suprema Corte de Justicia de la Nación y tomó grandes dimensiones hasta 1954 cuando los agentes aduanales lograron quedar exentos del pago del IsIM. ${ }^{21}$

El tercer motivo fue la integración vertical de las empresas que surgía a propósito del efecto cascada del ISIM. Para entender esta cuestión, vale la pena detenerse en un ejemplo presentado por Guillermo Flores, reconocido fiscalista de aquellos años quien retoma una transacción de compraventa realizada por un fabricante de telas que resume la TABLA 2:

TABLA 2

ISIM pagado por un productor de telas

\begin{tabular}{|c|c|c|c|c|}
\hline \multicolumn{2}{|c|}{ Compraba } & Procesaba & \multicolumn{2}{|c|}{ Vendía } \\
\hline Fibras y servicios & $\$ 100$ & \multirow{3}{*}{$\begin{array}{c}\text { Para fabricar } \\
\text { telas que... }\end{array}$} & Telas & $\$ 150$ \\
\hline ISIM del 4\% & $\$ 4$ & & ISIM del 4\% & $\$ 6$ \\
\hline Pagaba & $\$ 104$ & & Cobraba & $\$ 156$ \\
\hline
\end{tabular}

Fuente: Flores Meyer, Estudio analítico, 1982, p. 4.

El caso comienza asumiendo que el fabricante demandó fibras y servicios para iniciar su proceso productivo por un monto igual a 100 pesos. Debido a esa transacción y considerando la tasa del 4\% del IsIm que estaba vigente para 1973, debía pagar a sus proveedores 4 pesos por dicho concepto. De esta forma, su compra total ascendía a 104 pesos. Después, una vez concluido su proceso productivo, el precio de venta de las telas ascendía a 150 pesos que incluían tanto el gasto de los sueldos y salarios en que incurría (26 pesos), como su respectiva ganancia (20 pesos). Para efectuar la venta de las mismas, el productor debía cobrar al consumidor el ISIM del 4\% sobre el precio de venta, es decir, 150 pesos que en nuestro ejemplo asciende a 6 pesos. De esta forma, el precio final de venta alcanzaba los 156 pesos.

En su declaración, el productor descomponía este monto - que había recibido como ingreso por concepto de venta - en dos rubros: 150 pesos que representaban su precio de venta y seis pesos de impuesto. Bajo esta simple mecánica surgía un problema: los 4 pesos que este productor pagaba por concepto de ISIM a su proveedor, se convertían en un costo de producción en la medida en que el ISIM que declaraba y que cobró al consumidor (6 pesos) los entregó por completo al fisco. No tenía manera de recuperar, en pocas palabras, el IsIm que había pagado por comprar las fibras y servicios que demandó para echar a andar su proceso productivo. De este modo se acumulaba en cada transacción un monto que elevaba el precio final de cada bien.

En este sentido, autoridades hacendarias y contribuyentes subrayaban con sobrada razón que el efecto acumulativo (o en cascada) del IsIM incentivaba tanto

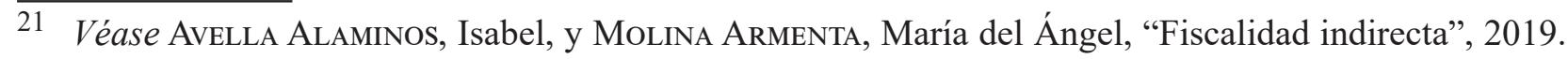


el incremento en el nivel de precios, como la integración vertical de la actividad económica que no venía bien con la intención de consolidar el mercado interno. Este inconveniente es claramente planteado por Paras y Jiménez:

Otro defecto de este impuesto era el de favorecer a la industria integrada en forma vertical, esto es, la que elaborase el producto y lo vendiese directamente al consumidor, ya que en el precio de sus mercancías sólo se incluiría el impuesto causado en la primera y única venta. Por lo contrario, los artículos que hubiesen pasado por varias empresas, antes de convertirse en productos terminados y listos para ser vendidos al consumidor final, incluirían en su precio de venta, el impuesto causado por cada una de las empresas por las que hubiera pasado; y con ello habría operado la imposición acumulativa. ${ }^{22}$

A partir del escenario descrito en la cita, la integración vertical se constituyó en una forma de evadir el pago del ISIM en tanto suponía un número menor de transacciones que redundaba en una menor recaudación. En relación con esta cuestión, el sistema de acreditamiento del IVA representó un avance cualitativo importantísimo para reducir la evasión fiscal y coadyuvar a revertir los bajos niveles de recaudación que reportaba la imposición indirecta. ¿De qué forma el sistema de acreditamiento permitió resolver estos problemas? En primer lugar, debemos indicar que, a través de éste, el impuesto pagado en cada etapa dejó de incidir en la definición de los costos de producción. Para comprender esta cuestión, retomemos el ejemplo anterior, pero ahora aplicando la tasa del 10\% con la que entró en vigor el IVA como presenta la TABLA 3.

TABLA 3

IVA pagado por un productor de telas

\begin{tabular}{|c|c|c|c|c|}
\hline \multicolumn{2}{|c|}{ Compraba } & Procesaba & \multicolumn{2}{c|}{ Vendía } \\
\hline Fibras y servicios & $\$ 100$ & \multirow{2}{*}{ Para fabricar telas } & Telas & $\$ 146$ \\
\cline { 4 - 5 } & $\$ 10$ & que... & IVA del $10 \%$ & $\$ 14.6$ \\
\cline { 5 - 5 } IVA del $10 \%$ & $\$ 110$ & Cobraba & $\$ 160.6$ \\
\hline Pagaba & &
\end{tabular}

Fuente: Flores Meyer, Estudio analítico, 1982, p. 10.

Como se observa, la transacción inicia nuevamente cuando el fabricante demandaba fibras y servicios por un monto igual a 100 pesos. Por esta transacción debía pagar a su proveedor 10 pesos por concepto de IVA. Así, su compra total ascendía a 110 pesos. Una vez que concluía su proceso productivo, vendía su bien en 146 pesos que estaban constituidos a su vez, por los 100 pesos que había gastado en fibras y servicios, por los 26 pesos que había gastado en sueldos y salarios y por 20 pesos de ganancia. Es importante hacer notar que, bajo el esquema del IVA, el fabricante de telas no incluía los 10 pesos que había pagado a sus proveedores. Así, el IVA calculado sobre 146 pesos, ascendía a 14.6 pesos dando lugar a

22 Paras Pagés, A., y JimÉnez Delgado, M., Impuesto, 1972, p. 7. 
un precio final de venta equivalente a 160.6 pesos. En resumidas cuentas, el proveedor le había traslado al productor un IVA equivalente a 10 pesos y éste, al efectuar su venta, había trasladado un IVA por 14.6 pesos. Bajo la lógica del sistema de acreditamiento que presentamos en el apartado anterior, el contribuyente sólo pagaba la diferencia entre el impuesto que había trasladado y el que le habían trasladado. En nuestro ejemplo, el contribuyente sólo enteraba al fisco 4.6 pesos. De esta manera, el productor, al recuperar los 10 pesos que le trasladaron de IVA, no tenía razón alguna para considerar ese pago dentro de sus costos de producción como sí lo hacía bajo el esquema del ISIM.

En segunda estancia, se debe anotar que, bajo esta dinámica, la incidencia del IVA sobre el nivel de precios era menor. A través del ejercicio comparativo que se especifica en la TABLA 4 y que muestra las transacciones realizadas por cuatro agentes (fabricante, intermediario comercial, detallista y consumidor), caemos en cuenta de que el efecto cascada del ISIM no está presente en el IVA. Si estas transacciones se realizan bajo el esquema del primero, el precio final del bien alcanza un nivel más alto que el estimado en el marco del IVA debido a que el ISIM - que no es recuperable - incrementa el precio de venta en cada etapa de la producción y distribución. En nuestro ejemplo, el precio del bien bajo el esquema del IsIM es de \$312; bajo el IVA, de \$310.

\section{TABLA 4}

Cuadro comparativo de la incidencia del ISIM y del IVA sobre los precios

\begin{tabular}{|c|c|c|c|}
\hline Transacciones & $\begin{array}{l}\text { CON } \\
\text { ISIM } \\
(4 \%)\end{array}$ & $\begin{array}{c}\text { CON } \\
\text { IVA } \\
(\mathbf{1 0 \%} \%)\end{array}$ & $\begin{array}{c}\text { Crédito } \\
\text { fiscal }\end{array}$ \\
\hline Los bienes y servicios adquiridos por fabricantes & $\$ 100$ & $\$ 100$ & \\
\hline ISIM que pagó y no recuperó el fabricante & 4 & & \\
\hline IVA que pagó pero que recuperó el fabricante & & & $\$ 10$ \\
\hline Sueldos y salarios que pagó el fabricante & 26 & 26 & \\
\hline Utilidad del fabricante & 20 & 20 & \\
\hline Precio al que vende al intermediario & 150 & 146 & \\
\hline ISIM que pagó el intermediario y no recuperó & 6 & & \\
\hline IVA que pagó el intermediario y recuperó & & & $\$ 14.60$ \\
\hline Sueldos que pagó el intermediario & 30 & 30 & \\
\hline Utilidad del intermediario & 14 & 14 & \\
\hline Precio al que vende al detallista & 200 & 190 & \\
\hline ISIM que pagó el detallista y no recuperó & 8 & & \\
\hline IVA que pagó el detallista y recuperó & & & $\$ 19$ \\
\hline Sueldos y salarios que pagó el detallista & 42 & 42 & \\
\hline Utilidad del detallista & 50 & 50 & \\
\hline Precio de venta al consumidor & 300 & 282 & \\
\hline
\end{tabular}




\begin{tabular}{|l|r|r|r|}
\hline & & & \\
\hline ISIM que paga el consumidor y que el detallista cubre al fisco & 12 & & \\
\hline $\begin{array}{l}\text { IVA que paga el consumidor y del cual sólo una parte cubre al } \\
\text { fisco el detallista }\end{array}$ & & 28.2 & \\
\hline Precio que paga el consumidor en total (Precio total) & $\mathbf{\$ 3 1 2}$ & $\mathbf{\$ 3 1 0}$ & \\
\hline
\end{tabular}

Fuente: Flores Mayer, Estudio analítico, 1982, p. 20. El cuadro aquí presentado contiene algunas modificaciones en términos del formato que fueron introducidas con la intención de lograr una lectura más clara.

Con un esquema que eliminaba el efecto cascada y su incidencia sobre los costos de producción y los precios, no había incentivo para la integración vertical de la actividad económica y se abría entonces la posibilidad de obtener una mayor recaudación. Además de este avance, el sistema de acreditamiento también significó una mejoría en el control de la recaudación en tanto que adquirió capital importancia para los contribuyentes, obtener documentos probatorios (factura, remisión o recibo) del IVA pagado en transacciones anteriores para poder así, obtener el respectivo crédito fiscal. Con este esquema, señalaba Pares en 1979, "a todo mundo le interesaría obtener facturas por sus adquisiciones para deducirle al fisco el impuesto causado sobre las compras y enterarle un neto menor, en vez de que el impuesto sobre la factura faltante le cueste a él. ${ }^{23}$ Desde esta perspectiva, como afirma, Turrent, el causante se convirtió en el propio inspector de otros causantes. ${ }^{24}$

La reglamentación relacionada con el sistema de acreditamiento comprendió varios artículos tanto de la ley federal del IVA como de su reglamento. De éstos, vale la pena recatar el inciso I y III del artículo $4^{\circ}$ que a la letra decían:

[...] Para que sea acreditable el impuesto al valor agregado deberán reunirse los siguientes requisitos:

I. Que corresponda a bienes o servicios estrictamente indispensables para la realización de actos por los que se deba pagar el impuesto establecido en esta Ley.

II. Que haya sido trasladado expresamente al contribuyente y conste por separado en documentación que satisfaga los requisitos que establece esta Ley y, en su caso, el Reglamento. ${ }^{25}$

Así mismo, se estableció como obligación del contribuyente la expedición de documentos probatorios que indicaran expresamente y por separado, el IVA que se trasladaba. ${ }^{26}$

Ahora bien, a través del primer requerimiento se evitaba que los causantes buscasen acreditar el IVA a través de gastos que no fueran estrictamente indispensables para la realización de las operaciones que gravaba el impuesto. Los asuntos

23 Paras Pages, Alberto; Ulibarri Arregui, S. y Calderón, Mario, et. al., "Estudio especial”, 1979.

24 Turrent Díaz, Eduardo, El impuesto al Valor Agregado, 1980, p. 16.

25 Ley del Impuesto al Valor Agregado, pp. 767-768.

26 Ibidem, p. 776. Según lo establecido en la fracción III del artículo 32 de la Ley del IVA de 1979, dichos documentos debían entregarse o enviarse a quién efectuó la contraprestación dentro de los 15 días naturales siguientes a la realización de la misma. 
cruciales, por menores que pareciesen, son el segundo requisito y la obligación del contribuyente de expedir los documentos probatorios. La importancia de hacer explicito el traslado del IVA, es decir, su cobro, resultaba mayúscula porque, de otro modo, no había posibilidad de obtener el crédito fiscal. En el análisis que Guillermo Flores realizó sobre este impuesto, se presenta un ejemplo bastante sencillo de esta cuestión:

[...] Por ejemplo, si en una factura se anota:

20 artículos B de precio unitario $\$ 1600.0$ que incluye IVA

$\$ 35,200$

Y al pie de la factura se anota:

\begin{tabular}{lr} 
Importe & $\$ 32,000$ \\
I.V.A & $\$ 3,200$ \\
Total & $\$ 35,200$ \\
\hline
\end{tabular}

Estos 3,200 no se podrán acreditar, para poder acreditarse deberá facturar así:

20 artículos B de precio unitario $\$ 1600.0 \mathrm{c} / \mathrm{u}$ $\$ 32,000$

I.V.A. $10 \%$ $\$ 3,200$

Cantidad a cobrar $\$ 35,200$

\section{Los $\$ 3,200$ son I.V.A acreditable ${ }^{27}$}

La trascendencia de esta cuestión, aunque pareciera un elemento de simple formato, consistió en ofrecer certeza al industrial y al comerciante de que el valor de las facturas se contaría como crédito fiscal. Al respecto, es importante mencionar que bajo el esquema administrativo del ISIM, la emisión de facturas donde constase que el impuesto fue trasladado al consumidor en el acto de compraventa no tenía un carácter obligatorio. En este sentido, la diferencia con el IVA radicó en el reconocimiento institucional de dicho documento para acreditar el impuesto que recuperaría el comerciante o industrial al momento de presentar su declaración. Esta cuestión es por demás relevante en términos políticos porque garantizaba a estos agentes económicos su papel como "recaudadores del impuesto" y no como sujetos mismos de la imposición del IVA. El consumidor representó, en realidad, el agente económico sobre el que efectivamente recayó esta figura tributaria. Evitar el conflicto con la iniciativa privada a través de la modificación al ISR, no era ninguna minucia en un contexto tenso entre ésta y el gobierno federal que databa del sexenio echeverrista. ${ }^{28}$

$\overline{27}$ Flores MaYer, Guillermo, Estudio, p. 166.

28 Véase Molina Armenta, María del Ángel, “El establecimiento”, 2019, p. 20. 
Con el establecimiento de documentos probatorios como requisitos para el acreditamiento, también se obtenía información por demás detallada sobre la actividad económica que podía ser procesada electrónicamente por las autoridades fiscales y lograr, en esa medida, un mayor control sobre la fiscalización. Además, se homogenizaba su formato con los documentos correspondientes en el ISR. En el artículo $8^{\circ}$ del Reglamento del IVA se dispuso que la documentación probatoria debía reunir los mismos datos que señalaban el Reglamento del ISR para los documentos que servían para comprobar gastos deducibles de dicho impuesto. ${ }^{29}$

Bajo esta dinámica se registraron incrementos importantes en la recaudación federal relacionada con la compraventa. Como se observa en la TABLA 5, durante los años transcurridos entre 1975 y 1984, es decir, durante los últimos cinco años de vigencia del ISIM y los primeros cinco del IVA, la participación porcentual del primero en los ingresos tributarios federales tendió a la baja, a reserva de 1977 cuando se observa una ligera recuperación. De 1975 cuando reportó una participación del $19.4 \%$ a 1979 que registró una del 18.7\%, se observan diminuciones continuas. En cambio, la del IVA fue ascendente: de 1980 a 1984, su aportación a los ingresos tributarios federales pasó del 19.9\% al 30.7\%. Tras cuatro años de su establecimiento ya comenzaba a definirse como la segunda columna fiscal de la federación pues reportaba una participación cercana al ISR. El ISIM, como también puede observarse, siempre mantuvo una distancia considerable de este último. Por ejemplo, en 1979, es decir, durante su último año de vigencia, la participación del ISR alcanzó los 43 puntos porcentuales que doblaron el 18.7\% del antecesor del IVA.

TABLA 5

Participación relativa del ISR, ISIM e IVA en los ingresos tributarios federales, 1975-1984

\begin{tabular}{|c|c|c|c|}
\hline Años & ISR & ISIM & IVA \\
\hline 1975 & 39.8 & 19.4 & - \\
\hline 1976 & 43.9 & 20.2 & - \\
\hline 1977 & 42.8 & 18.5 & - \\
\hline 1978 & 45.4 & 19.8 & - \\
\hline 1979 & 43.0 & 18.7 & - \\
\hline 1980 & 39.9 & - & 19.9 \\
\hline 1981 & 39.3 & - & 20.6 \\
\hline 1982 & 48.3 & - & 22.5 \\
\hline 1983 & 39.5 & - & 30.0 \\
\hline 1984 & 39.9 & - & 30.7 \\
\hline
\end{tabular}

Fuente: Elaboración propia con base en INEGI, Estadísticas, 2000, pp. 634-640.

29 Los datos solicitados eran: I. Nombre, domicilio y número de registro federal de causantes del enajenante o del prestador del servicio; II. Nombre y domicilio del adquirente o del prestatario del servicio; III. Fecha de la realización del acto o actividad; IV. Cantidad y clase de bienes enajenados, o descripción del servicio recibido y; V. Precio unitario, importe y valor total. Reglamento del Impuesto al Valor Agregado, 1980, p. 500. 
Un último elemento que nos interesa rescatar de estas modificaciones administrativas es la relación entre la actividad económica y la sensibilidad de la recaudación a la misma. A través de éstas, es posible que las variaciones en el Producto Interno Bruto (PIB) se hayan traducido en una mayor recaudación por concepto de imposición indirecta. Desafortunadamente, no contamos con muchos estudios que nos permitan sustentar esta hipótesis con rigurosidad. Sin embargo, no parece tan descabellada si consideramos que entre 1950 y 1960 , por cada punto porcentual de incremento en el PIB, la recaudación del ISIM se incrementó en $0.72 \% .{ }^{30}$ En cambio, el IVA reportó una elasticidad ingreso de 1.12 durante los primeros veinte años de vigencia. ${ }^{31} \mathrm{El}$ conocimiento minucioso y reflexivo de las consecuencias del sistema de acreditamiento sobre la recaudación federal es una tarea pendiente que rebasa las intenciones de esta investigación; pero lo cierto es que a través del IVA se coadyuvó a resolver el problema de recaudación del ISIM, definiendo al contribuyente y los documentos probatorios de sus declaraciones como eslabón clave de la misma como hemos mostrado.

\section{LA CUESTIÓN POLÍTICA DEL ACREDITAMIENTO: LA DEBILITADA SO- BERANÍA FISCAL DE LAS ENTIDADES FEDERATIVAS Y LA CONSOLI- DACIÓN DE LA CENTRALIZACIÓN TRIBUTARIA DEL COMERCIO Y LA INDUSTRIA}

La importancia del sistema de acreditamiento del IVA no radicó exclusivamente en su capacidad de incrementar la recaudación fiscal indirecta del Erario mexicano como hemos señalado. Si consideramos los actores que participan en el mismo, caemos en cuenta de la importancia que tuvo en la centralización tributaria del comercio y la industria. En este sentido, sostenemos la idea de que el acreditamiento consagró la dependencia de los erarios locales al federal en la imposición indirecta. Para sustentar esta idea es necesario que señalemos dos cuestiones.

La primera, de carácter administrativo, es la redefinición que implicó la sustitución ISIM-IVA en términos de las declaraciones que presentaban los contribuyentes al fisco. Sin intención de desconocer la importancia de las diferencias entre los elementos que componen ambas declaraciones, nos limitaremos a llamar la atención para los objetivos que perseguimos, en cómo se declaraba uno y otro. Consideremos el caso representativo de un causante cuyo negocio contaba con una casa matriz y una sucursal en diferentes entidades federativas. Comencemos ejemplificando este escenario a través de una de las declaraciones del IsIM de la Cía. Mueblera, S.A., constituida en enero de 1963 y que se dedicaba a la fabricación y venta de muebles de madera para el hogar. La empresa durante el mes de octubre de 1966 obtuvo 163,000 pesos por concepto de ventas realizadas en el Distrito Federal donde se ubicaba su casa matriz (Véase la IMAGEN 1); y 70, 500 pesos por las realizadas en Puebla, donde se localizaba la sucursal (Véase IMAGEN

\footnotetext{
30 Subsecretaría de Ingresos, Bases, 1973, Cuadro II.8.

31 CÁRDEnAs, Oscar, et. al., "Elasticidad", 2008.
} 
2). Según las disposiciones establecidas en el artículo 11 y 12 del ordenamiento del ISIM vigente para aquellos años, la compañía debía declarar y pagar el impuesto en el Distrito Federal sólo por aquellos ingresos obtenidos en la casa matriz. Los ingresos de las sucursales debían ser declarados y pagados en las oficinas locales donde estuvieran empadronados, es decir, en su lugar de residencia. ${ }^{32} \mathrm{De}$ este modo, como también muestra la IMAGEN 1, la mueblería pagó por concepto de ISIM, 4,890 pesos que le correspondían a la hacienda federal. Los ingresos obtenidos en la sucursal de Puebla fueron declarados y pagados en ese estado. Como muestra la IMAgen 2, el monto total ascendió a 2, 115 pesos. De éstos 1 , 269 pesos correspondían a la federación y 846 pesos a la hacienda local por concepto de participación.

El sustento normativo de esta dinámica se ubica en los convenios celebrados entre la Secretaría de Hacienda y las entidades hasta entonces coordinadas. En estos arreglos, éstas se comprometían a:

a) Establecer en la capital del Estado una Oficina Central de Empadronamiento encargada de expedir las cédulas respectivas que para su validez deberán ser firmadas también por un delegado Federal [...].

b) Enviar a la Secretaría de Hacienda, dentro de los primeros quince días de cada mes, un duplicado de las cédulas de empadronamiento del Estado, expedidas durante el mes inmediato anterior.

c) Remitir a la Secretaría de Hacienda, por conducto del delegado Federal de la misma, una copia de las declaraciones presentadas por los causantes para el pago del impuesto. La remisión de estas copias se hará dentro de los diez días siguientes a la fecha en que las autoridades locales reciban las declaraciones de los causantes y el pago del gravamen.

d) A depositar en las Sucursales, Agencias o Corresponsalías del Banco de México, S.A., que señale la Secretaría de Hacienda, y a disposición de la misma, dentro de los tres días siguientes a la fecha en que se reciba el pago del impuesto, el monto de las cantidades percibidas por concepto de la cuota federal de 18 al millar, y el $60 \%$ de recargos y multas.

e) A rendir a la Secretaría de Hacienda, dentro de los primeros diez días de cada mes, un estado general informativo, con especificación del impuesto, cuota adicional local, recargos y multas percibidos en el mes inmediato anterior; y a comprobar que se hizo la concentración de las cantidades que corresponden a la Federación. ${ }^{33}$

32 Subsecretaría de Ingresos, Ley federal, 1976, pp. 45-46.

33 Para 1970, sin considerar al Distrito Federal, las entidades coordinadas con la federación en materia de transacciones mercantiles eran: Quintana Roo, Baja California Norte, Aguascalientes, Morelos, Querétaro, Tlaxcala, Michoacán, Sinaloa, San Luis Potosí, Colima, Yucatán, Durango, Hidalgo, Campeche, Tabasco, Puebla y Guerrero. Véase "Modificación al Convenio de Coordinación para el cobro del Impuesto Sobre Ingresos Mercantiles en el Estado de Yucatán", DOF, 15 de octubre de 1958; "Modificación al Convenio de Coordinación para el cobro del Impuesto Sobre Ingresos Mercantiles en el Estado de Morelos", DOF, 1de noviembre de 1958; "Modificación al Convenio de Coordinación para el cobro del Impuesto Sobre Ingresos Mercantiles en el Estado de Campeche", DOF, 1 de noviembre de 1962; "Modificación al Convenio de Coordinación para el cobro del Impuesto Sobre Ingresos Mercantiles en el Estado de Durango", DOF, 22 de febrero de 1969. 
En el marco de estas disposiciones, el ingreso fiscal que la federación recibía por las compraventas realizadas al interior de la república, estaban mediadas por las administraciones locales. En nuestro ejemplo, como mostramos, era la tesorería general del estado la que cobraba también el impuesto federal.

\section{IMAGEN 1}

Declaración del ISIM en el Distrito Federal

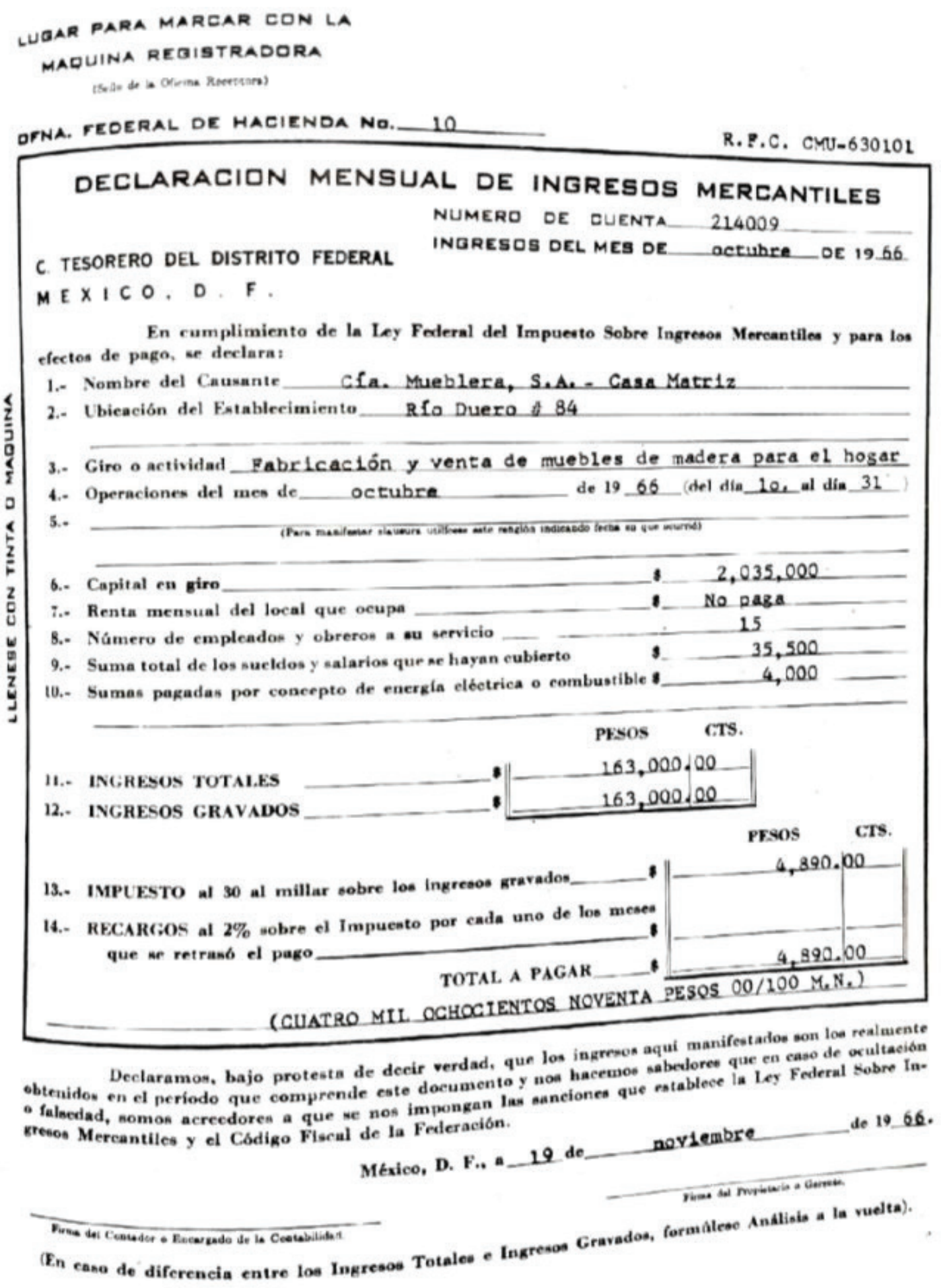

Fuente: Pliego, México fiscal, 1970, pp. 12161-12155. 
IMAGEN 2

Declaración del IsIm en Puebla

LEY FEDERAL DEL IMPUESTO SOBRE INGRESOS IERCANTILES PECLARACIONES IENSUALES DE LAS SUCLITSALES

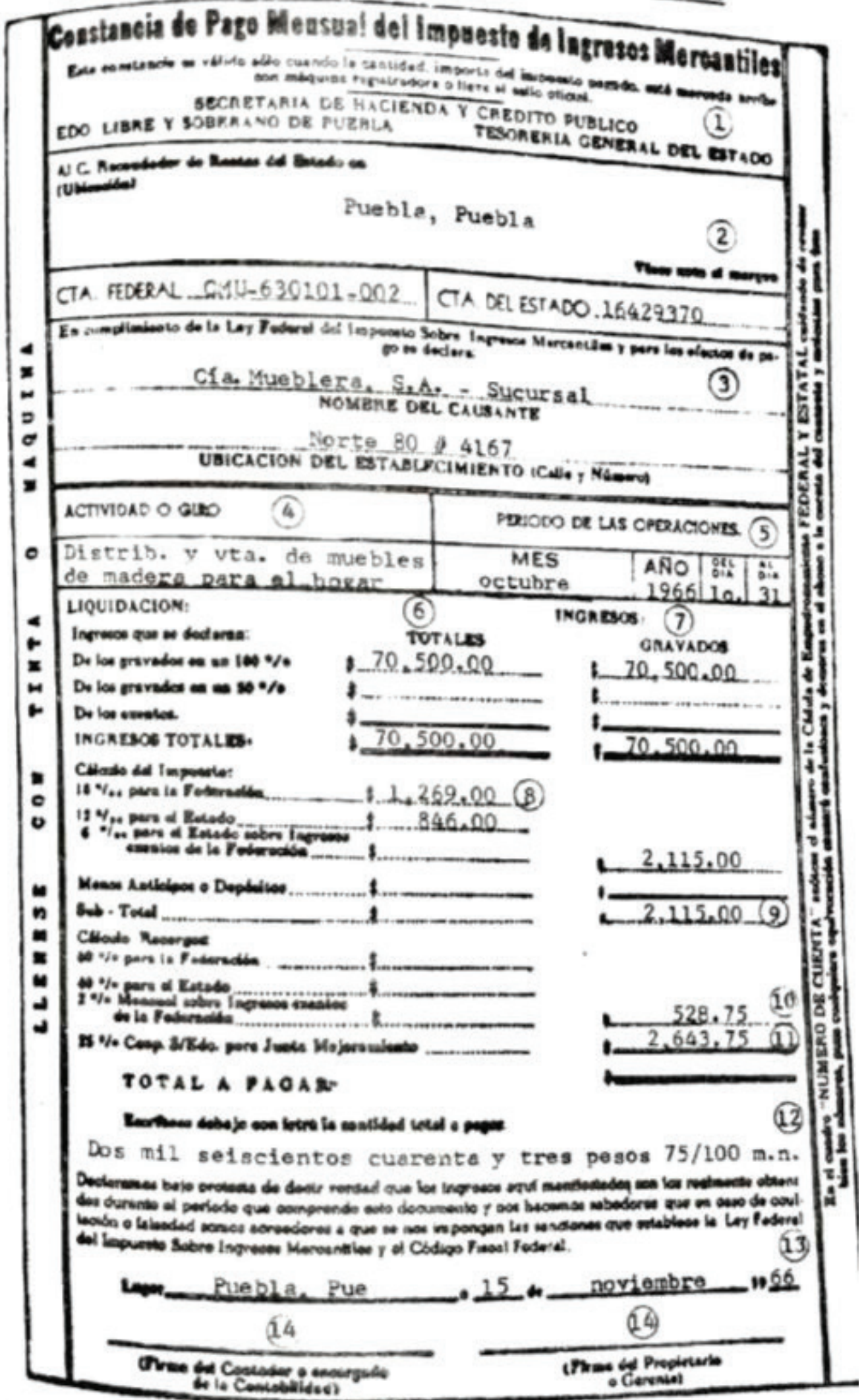

Fuente: Pliego, México fiscal, 1970, pp. 12161. 
En cambio, en las declaraciones del IVA, como se muestra en la IMAGEN 3, se consolidaban los ingresos de los contribuyentes en una sola declaración: tras indicar los datos generales del contribuyente como su nombre, denominación o razón social, domicilio fiscal, su Registro Federal de Causantes y el mes a declarar, se debían anotar el valor de todos los actos o actividades causadas por el IVA ${ }^{34}$ Para determinar el monto a declarar, al total del IVA pagado por el contribuyente (renglones 14 y 15), se le restaba el total del importe acreditable (indicado en el renglón 17). ${ }^{35}$ En la fracción IV del artículo 32 de la Ley federal del IVA de 1980 se señalaba: "[...] si un contribuye tuviere varios establecimientos, presentará por todo ellos una sola declaración, mensual o anual según se trate, en las oficinas autorizadas correspondientes al establecimiento principal". ${ }^{36}$

De suma importancia resulta señalar que las oficinas recaudadoras del IVA serían autorizadas por la Secretaría de Hacienda, según se indicaba en la Ley de Coordinación Fiscal que entró en vigor junto con éste en 1980. Esta disposición, cabe señalar, no era exclusiva para el IVA. En realidad, este último ordenamiento implicó importantes y complejas consecuencias sobre las relaciones fiscales de la nación. Para situar la importancia de esta modificación sobre las oficinas recaudadoras, podemos subrayar dos cuestiones de dicha ley. La primera es la reforma radical en la definición de las participaciones que recibían los estados coordinados: por primera vez, ésta se definiría con base en el total del ingreso fiscal nacional y no desde el ingreso parcial que se obtenía por cada ramo tributario. ${ }^{37}$

La segunda cuestión, consecuencia de la primera, tiene que ver con la administración local del impuesto federal. En la nueva Ley de Coordinación, si bien se identifica cierta descentralización administrativa en la medida en que invita a las entidades federativas a firmar convenios de colaboración en la materia que comprendían funciones relacionadas con la recaudación - como hemos ya dicho-, el registro de causantes y la fiscalización; también se apuntan disposiciones que definieron una completa centralización política en materia fiscal. Entre éstas destacan: la fijación de los gastos de administración que recibirían las entidades por parte de la federación por las actividades que realizasen en ese sentido; el reconocimiento de las autoridades fiscales de las entidades federativas como autoridades fiscales federales toda vez que ejercieran actos de administración de ingresos tributarios de dicho orden de gobierno y; la facultad de la Secretaría de Hacienda de fijar a las entidades, los criterios generales de interpretación y de aplicación de las disposiciones fiscales y de las reglas de colaboración administrativa. ${ }^{38}$

34 Renglón 10 para las actividades gravadas al 10\% y, renglón 11 para la zona fronteriza donde el IVA se estableció al 6\%.

35 En la segunda columna del formato que muestra la imagen 3, el contribuyente debía indicar, si era el caso, los saldos a favor pendientes de acreditar, así como los recargos por pago extemporáneo.

36 Ley del Impuesto al Valor Agregado, 1978, p. 776.

37 Véase Astudillo Moya, Marcela, "Las participaciones”, 1990. Aвoites Aguilar, Luis, Excepciones, 2003, cap. 6.

38 Ley de coordinación fiscal, 1978, pp. 4-5. 
La problemática más importante de señalar a propósito de esta gruesa comparación entre la administración de las declaraciones del ISIM y del IVA, es el papel de la territorialidad de la compraventa en la determinación del monto y disposición de la recaudación federal. Bajo el esquema administrativo del isim, el monto que ésta recibía por cada causante con operaciones en dos o más entidades federativas dependía del número de transacciones realizadas en cada estado; mientras que su disponibilidad, de la gestión realizada por las tesorerías generales para realizar la transferencia de recursos. En cambio, bajo el aparato administrativo del IVA, el territorio donde se realizaba la compraventa dejó de tener importancia para definir el monto y disposición de la recaudación en la medida en que el contribuyente declaraba sus ingresos consolidados (es decir, los obtenidos en la casa matriz y sucursales de manera conjunta) ante las oficinas, sí, locales, pero autorizadas, administradas y financiadas por la Secretaría de Hacienda.

\section{IMAGEN 3}

Declaración mensual del IVA

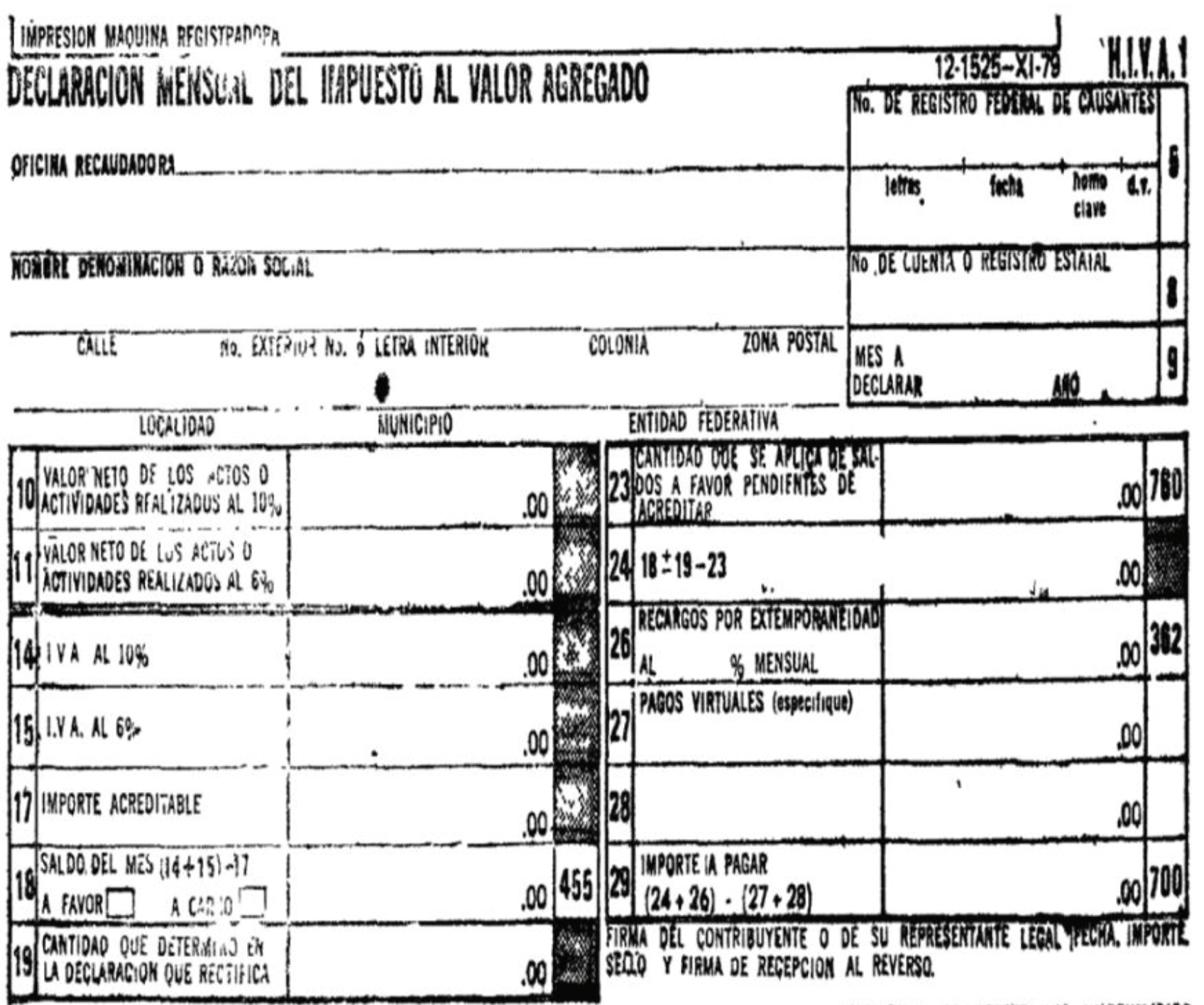

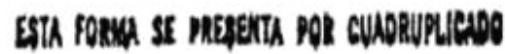



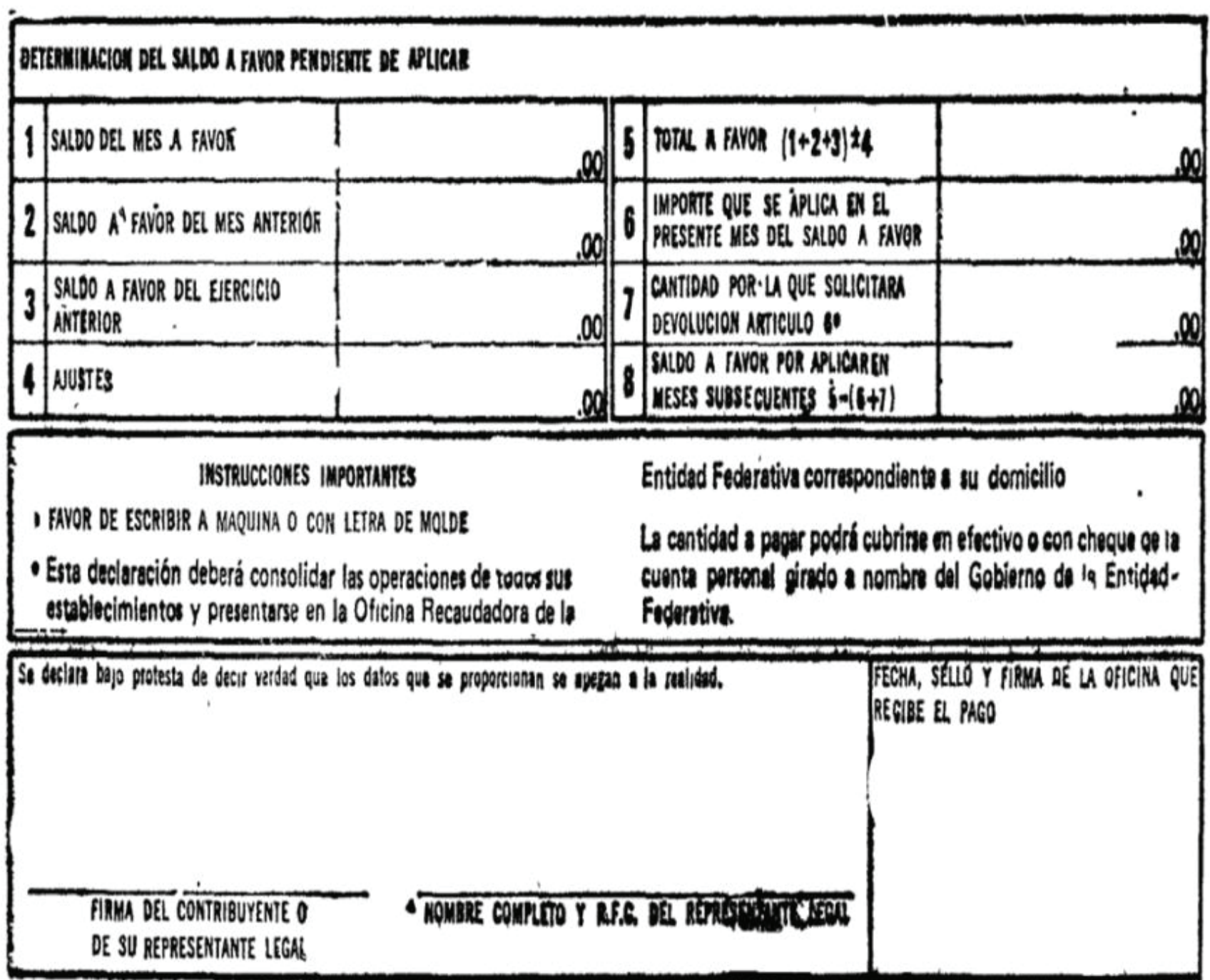

Fuente: DOF, 18 de diciembre de 1979.

La segunda cuestión, de carácter político, son los serios problemas que la federación enfrentó para centralizar el sistema tributario del comercio y la industria a través del ISIM. Como señalamos en el primer apartado, con el establecimiento de este último impuesto, las autoridades hacendarias federales buscaron concentrar dentro de su facultad fiscal la imposición del ramo. Al respecto cabe realizar algunas anotaciones. La primera es que el mecanismo gradual de coordinación que implicó el ISIM surgió precisamente de la importante oposición que las haciendas locales mostraron ante los esfuerzos centralizadores federales de los años veinte y treinta. Las disputas fiscales entre ambos niveles de gobierno en materia de comercio e industria comenzaron a propósito de la Primera Convención Nacional Fiscal de 1925, cuando la federación propuso reformar la Constitución para que el ramo correspondiera a su jurisdicción. Las entidades federativas, a pesar de participar en dicho encuentro, no estuvieron de acuerdo y la iniciativa de reforma se retiró del Congreso al año siguiente. Años después, tras la celebración de la Segunda Convención Nacional Fiscal de 1933 que resultó tan urgente con los efectos económicos de la crisis internacional de 1929, la federación 
intentó centralizar el ramo a través del establecimiento de un impuesto federal que debía discutirse previamente con los estados. A pesar de ser un mecanismo más flexible que la reforma constitucional anteriormente propuesta, las entidades federativas, se negaron de nuevo en defensa de su soberanía tributaria. No en balde, algunos delegados encabezados por el Estado de México, en una de las sesiones de la Segunda Convención, señalaban:

La existencia constitucional de un Estado, no se concibe sin la existencia de medios propios para poder subsistir; la asignación de obligaciones y facultades para éstos, la fijación de ciertos servicios públicos que deben prestar no se concibe sin los medios para realizarlo. Hay determinadas obras públicas, determinadas necesidades sociales, unas de carácter inapelables, otras urgentes, algunas necesarias que la federación no atiende, que no podría atender, de las cuales se encargan los Gobiernos locales, y el privar a éstos de realizarlas como consecuencia de las reformas que se plantean, equivale a supeditar el bienestar de los Municipios y de los Estados a lo que bien tengan en acordar, $[\ldots]$, los funcionarios Federales $[\ldots] .{ }^{39}$

Luego, se sumaron problemas a lo largo del camino con otros actores. Tras el conflicto encabezado por la CONCANACO que resultó en la reducción de la sobretasa al 1.2\% que señalamos en el apartado anterior, se acotó también el incentivo que los estados recibirían en caso de coordinación en la medida en que recibirían una participación menor de la recaudación federal del IsIM. Esta reducción explica en alguna medida porqué las entidades federativas de menores recursos fueron las primeras que se coordinaron al ISIM. Para 1957 sólo habían firmado convenio los estados de menor actividad económica entre los que se encontraban Morelos, Querétaro, Tlaxcala. Hidalgo, Quintana Roo y Aguascalientes. Desde ese año, hasta la década de los setentas, no se celebró ni un sólo convenio. Para 1970, es decir, veintidós años después de su establecimiento, aún no se coordinaban catorce entidades federativas entre las que se encontraban, evidentemente, aquellas con mayor actividad económica como Veracruz, Jalisco, Nuevo León, Chihuahua, Coahuila, Tamaulipas, Sonora y el Estado de México.

Fue el establecimiento de una tasa única del 4\% en el ISIM, lo que permitió que estos estados se coordinaran en 1973. En otras investigaciones sostenemos y desarrollamos la idea de que esta modificación que dejó atrás la composición de tasas que había estado vigente hasta ese momento, representó en realidad un mecanismo de coerción política que obligó a estas entidades federativas a firmar convenios de coordinación con la Secretaría de Hacienda. Lo que interesa subrayar en este sentido es que a través de la reforma de 1973 los estados quedaron completamente debilitados en términos de la distribución de facultades tributarias sobre el ramo, abriendo un escenario político menos conflictivo para la imposición del IVA. No en balde, se habían negado durante más de dos décadas. ${ }^{40} \mathrm{Al}$ respecto, Jorge Navarra Ayala, representante de Chihuahua en la Tercera Reunión de Tesoreros celebrada en ese mismo año, afirmaba que los estados que se habían mantenido renuentes a la coordinación se vieron obligados a firmar el respectivo

39 SHCP, Memoria Tercera, 1947, tomo III, p. 112.

40 Véase Molina Armenta, María del Ángel, "El establecimiento", 2019. 
convenio debido a la presión que se ejercería sobre los causantes a través de la tasa global del 4\%:

En efecto, con la imposición de la tasa federal única incrementada al 4\% con participación para los Estados que suscriben convenios con la Secretaría de Hacienda y Crédito Público [...], prácticamente indenunciables por parte de los Estados, ya que los contribuyentes no podrían soportar la carga de los impuestos locales al Comercio y a la Industria y Federal sobre Ingresos Mercantiles. De esta manera, el Gobierno Estatal que denunciara al Convenio tendría que enfrentarse a consecuencias políticas y económicas francamente insalvables $[\ldots]^{41}$

En este estado de cosas, la menor importancia que adquirió la territorialidad de la transacción económica para la recaudación y que se reflejó en el diseño de la declaración del IVA que recién abordamos, junto con la preponderancia que adquirieron los contribuyentes sobre el control de la misma que revisamos en el apartado anterior a través de las facturas, configuraron una consecuencia mucho más profunda en términos políticos: la federación, al menos para las cuestiones administrativas relacionadas con el cobro del IVA, supeditó por completo a las entidades federativas para dar mayor peso a los contribuyentes en las respectivas gestiones. Lo que debemos subrayar en todo caso, es que a través del sistema de acreditamiento del IVA se consagró el proceso de centralización en materia de industria y comercio en tanto que las entidades federativas no sólo perdieron cualquier facultad administrativa para el cobro del impuesto federal como al menos, lo tenían bajo el esquema del IsIM posterior a 1973, sino también, se posibilitó que las participaciones a las haciendas locales dejaran de asignarse con base en la actividad económica local como también sucedía bajo el esquema administrativo del mismo. ${ }^{42}$ En términos de la imposición indirecta, las oficinas de la hacienda local se reafirmaban como oficinas de recaudación federal. Las facturas y las declaraciones con las que se instrumentó el sistema de acreditamiento del IVA se constituyeron de este modo, en la expresión administrativa de la centralización fiscal.

\section{CONSIDERACIONES FINALES}

Del análisis que hemos desarrollado en este capítulo sobre el sistema de acreditamiento del IVA y las reformas administrativas que implicó en términos de los documentos probatorios y las declaraciones, surgen al menos dos tareas pendientes por realizar. La primera está relacionada con la Ley de Coordinación Fiscal de 1980, que además de entrar en vigor el mismo día que el IVA, denota un vínculo con éste que debe ser estudiado con sumo cuidado. Como hemos mencionado, a través del sistema de acreditamiento del IVA, con el que la territorialidad de las transacciones perdió importancia para la distribución del ingreso

41 Subsecretaría de Ingresos, Primer, 1973, pp. 210-211.

42 Bajo el esquema anterior a 1973 cada entidad federativa cobraba una participación de la recaudación federal del ISIM a través de una sobretasa de $1.2 \%$. Después, bajo el esquema de tasa única, la federación otorgaba $45 \%$ de la recaudación local. 
fiscal como sí sucedía con el ISIM, se coadyuvó a que la recaudación federal dejara de distribuirse por figura tributaria para comenzar a repartirse en función de un fondo único constituido por el total de ingresos fiscales federales, a saber, el Fondo General de Participaciones. Las implicaciones políticas de este viraje en la distribución del ingreso tributario no fueron de poca importancia porque la federación, a través de la Ley de Coordinación de 1980, consagró el pacto fiscal centralizado vigente hasta nuestros días. Acercarse a este vínculo político desde la administración pública representaría una aportación significativa para comprender cómo se definieron las instituciones que dieron funcionalidad a la centralización fiscal en nuestro país durante el siglo xx.

La segunda cuestión tiene que ver con las implicaciones - en términos amplios - de la reorganización administrativa que conllevó la introducción del IVA. Además del sistema de acreditamiento, existen diversas problemáticas cuyo análisis coadyuvaría, sin duda, a contar con una comprensión más compleja del cómo la federación se hizo de recursos a través de la administración relacionada con la imposición indirecta. Algunas de éstas son las campañas de divulgación que la federación impulsó entre 1979 y 1980 para facilitar la entrada en vigor del IVA, la reorganización de la estructura administrativa al interior de la Secretaría de Hacienda para dar espacio a los organismos que se encargarían del nuevo impuesto, la capacitación de los funcionarios que trabajarían en éstos e incluso las cuestiones relacionadas con la adquisición de la maquinaria que permitiría hacer el registro digital de las declaraciones. Así mismo, se puede analizar la descentralización administrativa implícita en el IVA, apenas esbozada en este capítulo. Cabría preguntarnos en este sentido, cómo se inscribieron las modificaciones relacionadas con el IVA en el proceso de reorganización administrativa que se impulsó a partir de la presidencia de Luis Echeverría. Todo apunta a identificar un binomio crucial entre la centralización del poder político en términos fiscales y un andamiaje administrativo eficiente, que no ha sido estudiado con perspectiva histórica para el caso de las finanzas públicas mexicanas del siglo Xx.

Una última anotación es de carácter historiográfico. Tras el análisis que presentamos en este capítulo y las problemáticas que aún están pendientes de desarrollar, no nos queda más que insistir en la necesidad de recuperar a la administración pública como ventana analítica para entender a la hacienda pública mexicana del siglo xx. Si bien ha sido una perspectiva fructífera para la comprensión de otros periodos de la historia fiscal nacional, no representa una propuesta extendida en los estudios contemporáneos. Este vacío, quizá responda también a que los historiadores económicos que nos hemos encargado de este periodo, hemos asumido equivocadamente que la administración hacendaria es una cuestión dada. Confiamos en que los planteamientos que aquí presentamos representen una invitación para avanzar en este sentido.

\section{BIBLIOGRAFÍA}

Aboites Aguilar, Luis, Excepciones y privilegios. Modernización tributaria y centralización en México, 1922-1972, México, Colmex, 2003. 
Aboites Aguilar, Luis y Unda Gutiérrez, Mónica, El fracaso de la reforma fiscal de 1961, México, Colmex, 2011.

Astudillo Moya, Marcela, "Las participaciones a los estados: clave de la coordinación fiscal en México", Investigación Económica, vol. 49, núm. 142, abril-junio 1990, pp. 213-233.

Becerril, Carlos, “Administrativizar la Hacienda Pública. La legislación tributaria del régimen santannista, 1853-1855”, Legajos, núm. 16, abril-junio 2013, pp. 35-60.

Beteta, Ramón, Tres años de política hacendaria. Perspectiva y acción (19471948-1949). Ciudad de México, México, Secretaría de Hacienda y Crédito Público, 1951.

CÁRdenas SÁnchez, Enrique, El largo curso de la economía mexicana. De 1780 a nuestros días. Ciudad de México, México, Fondo de Cultura EconómicaColmex, 2015.

CÁRdenas, Óscar; Ventosa-SAntauláRIA, Daniel y Gómez, Manuel, "Elasticidad ingreso de los impuestos federales en México: efectos en la recaudación federal participable", El Trimestre Económico, vol. 75, núm. 298(2), 2008, pp. 519-531.

Diario Oficial de la Federación, varias fechas.

Exposición de motivos de la Ley del Impuesto al Valor Agregado, El Trimestre Económico, vol. 46, núm. 183(3), 1979, pp. 763-766.

Flores Meyer, Guillermo, Estudio Analítico del IVA, México, Ediciones Contables y Administrativas, 1982.

García Alba Iduñate, Pascual, La evasión fiscal en México, México, UAMAzcapotzalco, 1982.

Gil VALDIVIA, Gerardo, "Notas sobre la introducción del Impuesto al Valor Agregado en México", Gaceta Informativa de Legislación y Jurisprudencia, 1979, 8(27), pp. 439-448.

Gracida Romo, Elsa, El siglo XX mexicano. Un capitulo de su historia, 19401982. Ciudad de México, México, Facultad de Economía, UNAM, 2002.

Ibarra Muñoz, David, Política financiera y hacendaria. Ciudad de México, México, Secretaría de Hacienda y Crédito Público, 1980.

Instituto Mexicano de Ejecutivos de Finanzas, Panel para la presentación de la campaña del Impuesto al Valor Agregado, vol. 2, México, 1979.

Instituto Nacional de Estadística, Geografía e Informática (INEGI), Estadísticas Históricas de México, Tomo I, México, 2000.

JÁuregui, Luis, La Real Hacienda de Nueva España: su administración en la época de los intendentes, 1786-1821, México, Facultad de Economía, UNAM, 1999.

Ley de coordinación fiscal en Diario Oficial de la Federación, 27 de diciembre de 1978.

Ley del impuesto al valor agregado en El Trimestre Económico, vol. 46, núm. 183(3), 1979, pp. 766-780. 
López TiJerina, José G., "Coordinación fiscal en el Impuesto Sobre Ingresos Mercantiles. Origen y efectos", en Revista El economista mexicano, México, vol. IX, núm. 3, abril-mayo 1973, pp. 112-122.

Molina Armenta, María del Ángel, "El Establecimiento Del IVA En México: Un Problema Político-Económico, 1968-1980”, América Latina en la Historia Económica, 27 (1), e987, 2019.

Molina Armenta, María del Ángel, "La participación de comerciantes e industriales en el establecimiento y diseño del Impuesto Sobre Ingresos Mercantiles, 1947-1948" en Celaya NÁndez, Yovana y Márquez, Graciela, De contribuyentes y contribuciones en la fiscalidad mexicana, siglos XVIII-XX, México, Colmex-Universidad Veracruzana, 2018, pp. 357-397.

Molina Armenta, María del Ángel, "La coordinación del sistema tributario del comercio y la industria en México: el Impuesto Sobre Ingresos Mercantiles (ISIM), 1947-1980", tesis de doctorado en Historia Moderna y Contemporánea, México, Instituto de Investigaciones Dr. José María Luis Mora, 2016.

Molina Armenta, María del Ángel y Avella Alaminos, Isabel, "Fiscalidad indirecta y contribuyentes en México: el conflicto entre los agentes aduanales y la Secretaría de Hacienda en torno al Impuesto Sobre Ingresos Mercantiles (1949-1954)" en Romero Ibarra Ma. E. y Molina Armenta, Ma. del A., Legislación y conflicto: actores, entornos y administración hacendaria en México, siglos XIX y XX, México, Facultad de Economía-UNAM, 2000, pp. 267-315.

Moreno Brid, Juan Carlos y Ros Bosch, Jaime, Desarrollo y crecimiento en la economía mexicana. Una perspectiva histórica, México, FCE, 2010.

Paras Pagés, A. y Jiménez Delgado, M., Impuesto al Valor Agregado, Ciudad de México, México, Centro de Investigación Tributaria, 1972.

Paras Pages, Alberto; Ulibarri Arregui, S. y Calderón, Mario, "Estudio especial ante el nuevo Impuesto al Valor Agregado" en Instituto Mexicano de Ejecutivos de Finanzas, Panel, México, 1979.

Pliego, Eduardo, México fiscal: Impuesto Sobre Ingresos Mercantiles, s.e. 1970. Reglamento de la Ley del Impuesto al Valor Agregado en El Trimestre Económico, vol. 47, núm. 186(2), 1980, pp. 499-513.

Subsecretaría de Ingresos, Programa de actividades bienio 1971-1972. Evaluación de resultados al 30 de junio de 1972, Secretaría de Hacienda y Crédito Público, México, 1972.

Subsecretaría de Ingresos, Primer Informe sobre las relaciones fiscales entre la Federación y los Estados, México, Secretaría de Hacienda y Crédito Público, 1973.

Subsecretaría de Ingresos, Bases para la Regionalización de la Administración Pública Federal, Secretaría de Hacienda y Crédito Público, México, 1973. Subsecretaría de Ingresos, Ley Federal del Impuesto Sobre Ingresos Mercantiles. Evolución histórica, Secretaría de Hacienda y Crédito Público, México, 1976. 
Turrent DíAz, Eduardo, El Impuesto al Valor Agregado: el caso de México, México, DCSyH-UAM Azcapotzalco, 1980.

YÁÑEz Ruíz, Manuel, El problema fiscal en las distintas etapas de nuestra organización política, tomo IV, México, SHCP, 1958.

Esta obra está bajo licencia internacional Creative Commons ReconocimientoNo-Comercial-CompartirIgual 4.0.

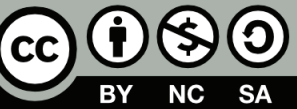

